\title{
Examining the influence of the implementation of Major Function-oriented Zones on built-up area expansion in China
}

\author{
LIU Wenchao ${ }^{1,2,3}$, "LIU Jiyuan ${ }^{1},{ }^{*}$ KUANG Wenhui ${ }^{1}$, NING Jia ${ }^{1}$ \\ 1. Key Laboratory of Land Surface Pattern and Simulation, Institute of Geographic Sciences and Natural \\ Resources Research, CAS, Beijing 100101, China; \\ 2. College of Urban and Environment Science, Tianjin Normal University, Tianjin 300387, China; \\ 3. University of Chinese Academy of Sciences, Beijing 100049, China
}

\begin{abstract}
China had implemented the national strategies for Major Function-oriented Zones (MFOZs) to realize the goal of national sustainable development since 2010. This study analyzed and compared spatio-temporal characteristics and differences in built-up area for China's MFOZs using a China's Land Use Database (CLUD) derived from high-resolution remotely sensed images in the periods of 2000-2010 and 2010-2013. To sum up: (1) The percentage of built-up area in each of the MFOZs was significantly different, revealing the gradient feature of national land development based on the distribution of the main functions. (2) Annual growth in built-up area in optimal development zones (ODZs) decreased significantly during 2010-2013 compared with the period 2000-2010, while annual growth in built-up area in key development zones (KDZs), agricultural production zones (APZs) and key ecological function zones (KEFZs) increased significantly. (3) In ODZs, the average annual increase in built-up area in the Yangtze River Delta region was significantly higher than in other regions; the average area increase and rate of increase of built-up area in KDZs was faster in the western region than in other regions; average annual area growth of built-up area in APZs in the northeast, central and western regions was twice as high as the previous decade on average; the annual rate of change and increase in the dynamic degree of built-up area were most notable in KEFZs in the central region. (4) The spatial pattern and characteristics of built-up area expansions in the period 2010-2013 reflected the gradient feature of the plan for MFOZs. But the rate of increase locally in built-up area in ODZs, APZs and KEFZs is fast, so the effective measures must be adopted in the implementation of national and regional policies. The conclusions indicated these methods and results were meaningful for future regulation strategies in optimizing national land development in China.
\end{abstract}

Keywords: Major Function-oriented Zones; satellite remote sensing; land use change; development of urban and town built-up area; China

Received: 2016-04-21 Accepted: 2016-12-30

Foundation: Key Project of National Natural Science Foundation of China, No.41371409; National Key Technology R\&D Program, No.2013BAC03B00

Author: Liu Wenchao (1986-), PhD and Lecturer, specialized in remote sensing of natural resources and environment, land use and cover change (LUCC) and ecological effect. E-mail: dorayliu@163.com

"Corresponding author: Liu Jiyuan (1947-), Professor, E-mail: liujy@igsnrr.ac.cn Kuang Wenhui (1978-), PhD and Associate Professor, E-mail: kuangwh@igsnrr.ac.cn 


\section{Introduction}

Human alterations to ecosystems and landscapes have led to changes in the global climate and environment, which in turn has affected the ability of the biosphere to sustain life. Land Use and Cover Change (LUCC) has attracted widely attention worldwide as a major cause of global environmental change (Turner et al., 1995; Foley et al., 2005; Salazar et al., 2015; Liu et al., 2014; Shi et al., 2000). Since the 1990s, LUCC research has become a key field of global environmental research. In 1995, the International Geosphere-Biosphere Program (IGBP) and International Human Dimensions Program (IHDP) jointly launched the Land-Use and Land-Cover Change-Science/Research Plan, which proposed three prior research themes including the land-use change driving forces, the land-coverage change driving forces and developing a regional and global model (Lambin et al., 1995; Turner et al., 1995). In late 2005, the Global Land Project, a core research program jointly proposed by the IGBP and IHDP, was officially launched, the focus of which was to study the relationship between humans and earth system in land systems and attempt to measure and model the coupled human-environment system, thereby helping humans to enhance their understanding of changes to the land system and its social and economic consequences (GLP, 2005). Therefore land-use and land-change research had widely been focused on the coupled human-environment system (McMahon et al., 2005; Liu et al., 2005).

Rapid urbanization and industrialization since the late 1970s have resulted in accelerated land use changes across China. Widespread resources exploitation and sprawling development that ignores their sustainability has resulted in the deterioration of the ecological environment (Lu et al., 2009; Chen et al., 2004). In order to effectively protect resource and realize the sustainable development of China, China proposed a set of guiding principles to serve government regulations on national top-down space protection, involving a practical, innovative and forward-looking draft plan for Major Function-oriented Zones (MFOZs) in China. Back in 2010, this plan was published by the State Council as the National Plan for Major Function-oriented Zones, and was subsequently upgraded to the Major Function-oriented Zones Strategy in the 12th Five-Year Plan for National Economic and Social Development published by the National People's Congress. It was later referred to as the "Major Function-oriented Zones system" in the resolution from the Third Plenary Session of the 18th CPC Central Committee (Fan, 2015). The plan divided national land into four categories and two levels based on regional functions and according to specific development content. The four categories were urbanization zones, agricultural production (food security) zones, key ecological function (ecological security) zones, and natural and cultural heritage protection zones, while the two levels were national and provincial (Fan et al., 2012; Fan et $a l ., 2012)$. These were then divided into four Major Function-oriented Zones based on development methods: optimal development zones, key development zones, restricted development zones and prohibited development zones. The development method, level of protection and primary development tasks of each type of Major Function-oriented Zones are different.

Monitoring national land-use and land-cover change using high resolution remotely sensed images had the great significance for evaluating the spatio-temporal characteristics of built-up area in different MFOZs in China (Liu, 1996; Liu et al., 2003). On the basis of a CLUD with a scale of 1:100,000 comprising data from 2000 and 2010 and a $1 \mathrm{~km}$ proportion 
component classification grid database interpreted by our research group (Liu et al., 2010; Kuang et al., 2013; Zhang et al., 2012), we updated the 2013 national land use database. Then we developed the database of built-up area for the two periods 2000-2010 and 2010-2013. Based on these data sets, we analyzed the spatiotemporal characteristics of built-up area in China from 2000 to the present and revealed regional differences in the development of built-up area in different MFOZs for the periods 2000-2010 and 2010-2013, as well as the adjusting degree to which they correspond to the plan for MFOZs, with a view to providing policy support for future regulation strategies in optimizing national land development in China.

\section{Datasets and methods}

\subsection{Land use datasets}

On the basis of CLUD from 2000 and 2010 (Liu et al., 2010; Kuang et al., 2013; Zhang et al., 2012), we updated the land use datasets in 2013 by human-computer interactive method. This method specifically identified the land use changing objectives by comparing the remote sensing images for two periods in 2010 and 2013. We updated a national land use database with a scale of 1:100,000. Then we developed the database of built-up area for the two periods 2000-2010 and 2010-2013. High resolution remote sensing image covered the whole country were used to update CLUD. Although data from Landsat TM did not cover the whole of China or was of poor quality for some regions, data was used from the Resources satellite third (ZY3) and the high precise image from the Google Earth to supplement it, and better data from different sensor types and time phases was selected as appropriate to improve interpretation and mapping accuracy. The vector datasets were applied to extract and calculate the area of each type of land including cultivated land, woodland, grassland, water body, urban and industrial land, and unused land and their 25 sub-class from CLUD classification system. To ensure the quality and accuracy of data, a nationwide field survey was carried out during the preliminary interpretation of the 2013 data, and samples equivalent to $10 \%$ of all counties were randomly selected for the field survey data and field records for the sake of verifying accuracy. The accuracy of first-level land categories was higher than $94.3 \%$ and that of sub-class was higher than $91.2 \%$, which was enough for 1:100,000 scale mapping accuracy.

In addition, the study further divided built-up area into three second-level land use categories, namely urban land, rural residential land, and factory, mine and transportation land. Urban land refers to built-up areas of land in large, medium-sized and small cities and towns. Rural residential land refers to land of residential areas smaller than towns. Factory, mine and transportation land refers to land occupied by factories, mines, large industry, oilfields and quarries, or special sites such as airports and ports.

\subsection{China's Major Function-oriented Zones}

The data on Major Function-oriented Zones used in this study mainly came from the National Plan for Major Function-oriented Zones issued by the State Council and the Scheme for Major Function-oriented Zoning in China (V1.0) (Fan, 2015). Major Function-Oriented Zones were divided into optimal development zones, key development zones, restricted de- 
velopment zones and prohibited development zones according to their development methods, and restricted development zones were further divided into agricultural production zones and key ecological function zones. Optimal development zones, such as the Bohai Rim, the Yangtze River Delta and Pearl River Delta regions, are relatively strong overall, have large-scale economies, relatively sound systems of urban and rural construction, relatively strong internal economic ties and a strong scientific foundation for innovation. Key development zones, such as the middle reaches of the Yangtze River, central and southern Hebei and Central Plains economic zone, are regions that usually have strong economic foundations, the beginnings of systems for urban development and can promote development in surrounding areas. Restricted development zones are agricultural production zones and key ecological function zones where large-scale and intensive urban construction are restricted. Prohibited development zones are areas of strict ecological protection where industrialization and urbanization are prohibited (Fan, 2015). Since prohibited development zones are function-oriented zones superimposed on the former three types of function-oriented zones, and there is relatively few of them compared to the other types, this study chose not to deal with them. MFOZs are also designated as national-level or provincial-level zones based on the regional function hierarchy, and this paper focuses on national-level Major Function-oriented Zones, with no consideration given to provincial-level zones. The Draft of Major Function-oriented Zoning in China (V1.0) primarily dealt with provincial administrative zones. But attempts to coordinate with other indicators and plans meant that some zones had two or more zoning classifications. Where this study has dealt with provincial administrative zones, zones that contain two or more types of major functions have been removed, leaving only those counties that have one type of major function (Figure 1 and Table 1).

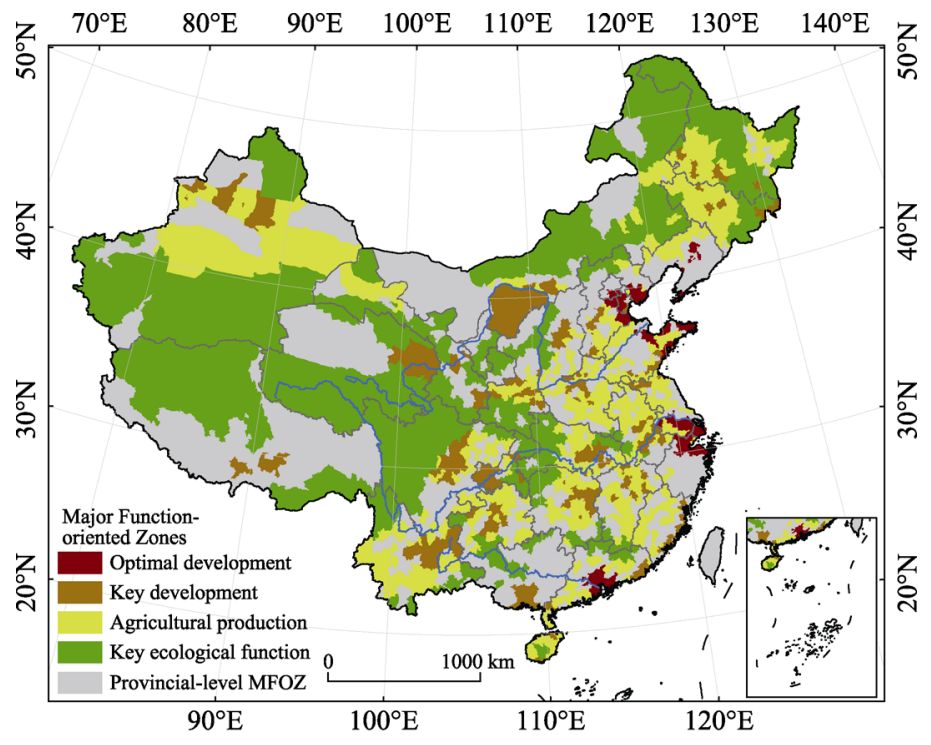

Figure 1 Major Function-oriented Zones of China (Fan, 2015)

\subsection{National developing zones}

In order to better reveal the characteristics and regional differences between each major function-oriented zone, this study divided China into four major zones (eastern, central, 
Table 1 The summary on Major Function-oriented Zones

\begin{tabular}{|c|c|c|c|c|}
\hline \multirow{2}{*}{ National-level functions } & \multicolumn{2}{|c|}{ Number of counties } & \multicolumn{2}{|c|}{ Land area } \\
\hline & Number & Percentage & $\left(\times 10^{4} \mathrm{~km}^{2}\right)$ & Percentage $(\%)$ \\
\hline Optimal development zones & 134 & 8.50 & 13.87 & 2.15 \\
\hline Key development zones & 361 & 23.46 & 67.76 & 10.51 \\
\hline Agricultural production zones & 692 & 41.98 & 181.90 & 28.21 \\
\hline Key ecological function zones & 419 & 26.06 & 381.25 & 59.13 \\
\hline
\end{tabular}

Note: The number of counties is taken from statistics provided in the 2012 edition of the China county territories administrative boundary vector data, and statistical results are not consolidated with administrative districts in accordance with municipal districts.

western and northeastern regions - see Figure 2 and Table 2) based on economic and social development factors. As the majority of optimal development zones are located along the coast, during the discussion of optimal development zones we have subdivided them into those in the Beijing-Tianjin-Hebei region, the Yangtze River Delta, the Pearl River Delta, central and southern Liaoning, and the Shandong Peninsula.

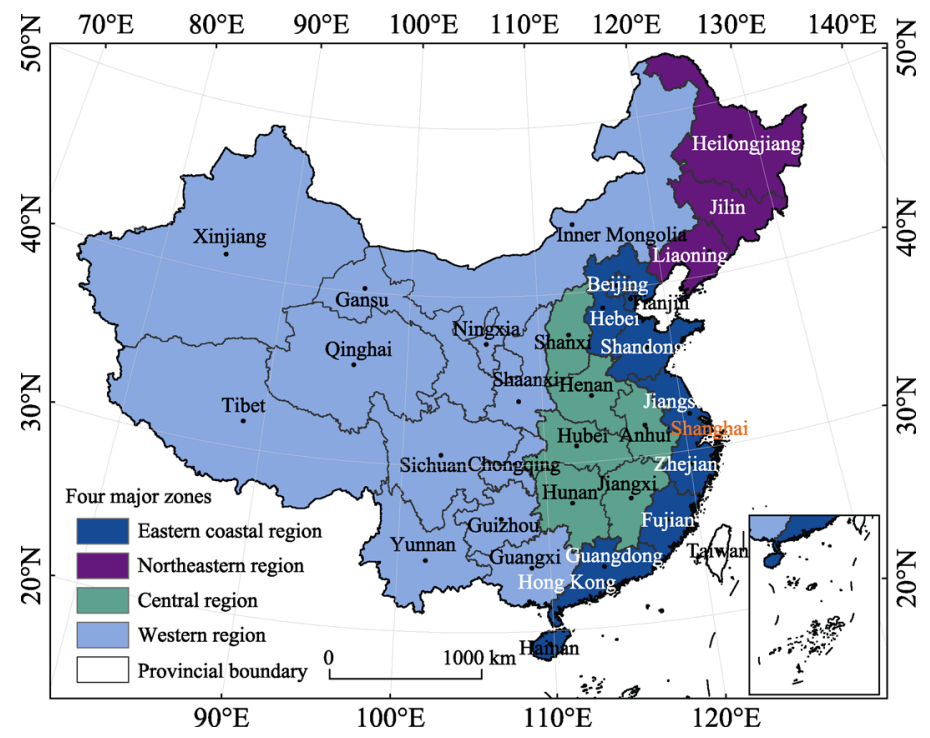

Figure 2 The distribution of major development zones

Table 2 Area and percentage of built-up area of Major Function-oriented Zones in 2013

\begin{tabular}{lccc}
\hline & $\begin{array}{c}\text { Major Function-oriented } \\
\text { Zones area }\left(\times 10^{4} \mathrm{~km}^{2}\right)\end{array}$ & $\begin{array}{c}\text { Built-up area } \\
\left(\times 10^{4} \mathrm{~km}^{2}\right)\end{array}$ & $\begin{array}{c}\text { Proportion of national } \\
\text { land area }(\%)\end{array}$ \\
\hline Optimal development zones & 13.87 & 3.74 & 27.02 \\
Key development zones & 67.76 & 4.25 & 6.27 \\
Agricultural production zones & 181.90 & 7.61 & 4.18 \\
Key ecological function zones & 381.25 & 1.63 & 0.43 \\
\hline
\end{tabular}

\subsection{Rate and dynamic degree of built-up area expansion}

In order to better show the speed and intensity of development of built-up area, this study used the indicators "built-up area expansion rate" and "dynamic degree of built-up area expansion", both of which are stated as a percentage per year $(\% / y r)$. The formula for calcu- 
lating the built-up area expansion rate is as follows:

$$
K=\left\{\sum_{i j}^{n}\left(\Delta S_{i j} / S_{i}\right)\right\} \times(1 / t) \times 100 \%
$$

where $S_{i}$ is the area at the start of monitoring built-up area, $\Delta S_{i j}$ is the total area of changed land type from and to built-up area during the monitored period, and $t$ is time. The rate of change of built-up area, $K$, therefore reflects the built-up area expansion rate within the study area during the certain period.

The formula for calculating the dynamic degree of built-up area expansion is as follows:

$$
S=\left\{\sum_{i j}^{n}\left(\Delta S_{i-j} / S_{a}\right)\right\} \times(1 / t) \times 100 \%
$$

where $S_{a}$ is the study area, $\Delta S_{i-j}$ is the total area of changed land type from and to built-up area during the monitored period, and $t$ is time. $S$ is the dynamic degree of built-up area expansion, which reflects the intensity of change from others to built-up area within the study area during the certain period.

\section{Results and analysis}

\subsection{Distribution of built-up area from Major Function-oriented Zones in $\mathbf{2 0 1 3}$}

The total area of built-up area in national Major Function-oriented Zones was $17.22 \times 10^{4}$ $\mathrm{km}^{2}$ in 2013 , accounted for $1.79 \%$ of China's land area. Of this, optimal development zones, key development zones, agricultural production zones and key ecological function zones accounted for $3.74 \times 10^{4} \mathrm{~km}^{2}, 4.25 \times 10^{4} \mathrm{~km}^{2}, 7.61 \times 10^{4} \mathrm{~km}^{2}$ and $1.63 \times 10^{4} \mathrm{~km}^{2}$, respectively, or $27.02 \%, 6.27 \%, 4.18 \%$ and $0.43 \%$, respectively, of the total land area within each of their function-oriented zones (Table 3). It is therefore possible to see the gradient feature of land development in different MFOZs. The area proportion of built-up area sub-class in different Major Function-oriented Zones is clearly different. The amount of urban land in optimal development zones has reached $50.82 \%$, which reflects the urban-centered development model in those regions. The area proportion of urban land, rural residential land and land for factories, mines and transportation in key development zones was 36.4\%, $44.41 \%$ and $19.19 \%$, respectively, which reflected the equal condition on urban, rural and industrial development in key development zones. Rural residential areas accounted for $71.03 \%$ of agricultural production zones and $68.01 \%$ of key ecological function zones, which reflect the fact that the focus of these two types of zones is on rural development (Table 4). Thus, the area proportion of built-up area sub-class clearly reflected the different development stages of the MFOZs.

Table 3 The percentage of sub-classes of built-up area from Major Function-oriented Zones in 2013

\begin{tabular}{lcccc}
\hline & $\begin{array}{c}\text { Area of built-up } \\
\text { area }\left(\times 10^{4} \mathrm{~km}^{2}\right)\end{array}$ & $\begin{array}{c}\text { Proportion of } \\
\text { urban land } \\
(\%)\end{array}$ & $\begin{array}{c}\text { Proportion of } \\
\text { rural residen- } \\
\text { tial land (\%) }\end{array}$ & $\begin{array}{c}\text { Proportion of land used } \\
\text { for factory, mining and } \\
\text { transportation }(\%)\end{array}$ \\
\hline Optimal development zones & 3.74 & 50.82 & 31.82 & 17.35 \\
Key development zones & 4.25 & 36.40 & 44.41 & 19.19 \\
Agricultural production zones & 7.61 & 18.33 & 71.03 & 10.64 \\
Key ecological function zones & 1.63 & 16.85 & 68.01 & 15.14 \\
\hline
\end{tabular}


Table 4 The related indexes of urban expansion from Major Function-oriented Zones in 2000-2010 and 20102013

\begin{tabular}{|c|c|c|c|c|}
\hline Zones & $\begin{array}{l}\text { Total area of } \\
\text { MFOZs }\left(\mathrm{km}^{2}\right)\end{array}$ & Indicator & $2000-2010$ & 2010-2013 \\
\hline \multirow{4}{*}{$\begin{array}{l}\text { Optimal devel- } \\
\text { opment zones }\end{array}$} & \multirow{4}{*}{$138,677.75$} & Area of change $\left(\mathrm{km}^{2}\right)$ & 9863.24 & 3277.02 \\
\hline & & Annual area of change $\left(\mathrm{km}^{2} / \mathrm{yr}\right)$ & 986.32 & 1092.34 \\
\hline & & Built-up area annual rate of change $(\% / y r)$ & 4.07 & 3.20 \\
\hline & & Built-up area dynamic degree $(\% / y r)$ & 0.71 & 0.79 \\
\hline \multirow{4}{*}{$\begin{array}{l}\text { Key develop- } \\
\text { ment zones }\end{array}$} & \multirow{4}{*}{$677,553.16$} & Area of change $\left(\mathrm{km}^{2}\right)$ & 8300.64 & 5238.82 \\
\hline & & Annual area of change $\left(\mathrm{km}^{2} / \mathrm{yr}\right)$ & 830.06 & 1746.27 \\
\hline & & Built-up area annual rate of change $(\% / y r)$ & 2.86 & 4.68 \\
\hline & & Built-up area dynamic degree $(\% / y r)$ & 0.12 & 0.26 \\
\hline \multirow{4}{*}{$\begin{array}{l}\text { Agricultural } \\
\text { production } \\
\text { zones }\end{array}$} & \multirow{4}{*}{$1,819,041.33$} & Area of change $\left(\mathrm{km}^{2}\right)$ & 6551.95 & 5016.57 \\
\hline & & Annual area of change $\left(\mathrm{km}^{2} / \mathrm{yr}\right)$ & 655.19 & 1672.19 \\
\hline & & Built-up area annual rate of change $(\% / y r)$ & 1.02 & 2.35 \\
\hline & & Built-up area dynamic degree $(\% / y r)$ & 0.04 & 0.09 \\
\hline \multirow{4}{*}{$\begin{array}{l}\text { Key ecological } \\
\text { function zones }\end{array}$} & \multirow{4}{*}{$3,812,537.64$} & Area of change $\left(\mathrm{km}^{2}\right)$ & 1449.10 & 1337.47 \\
\hline & & Annual area of change $\left(\mathrm{km}^{2} / \mathrm{yr}\right)$ & 144.91 & 445.82 \\
\hline & & Built-up area annual rate of change $(\% / y r)$ & 1.07 & 2.98 \\
\hline & & Built-up area dynamic degree $(\% / y r)$ & 0.004 & 0.012 \\
\hline
\end{tabular}

In 2013, built-up area of optimal development zones was mainly located in Beijing and Tianjin of the Beijing-Tianjin-Hebei region, the Yangtze River Delta and the Pearl River Delta, and crossing area across central and southern Liaoning and the Shandong Peninsula. Built-up area of key development zones was mainly located in eastern coastal regions, Tianjin Binhai New Area, southern Hebei, the border region between Shandong and Jiangsu, central Shanxi, northern Henan and eastern Hubei, with relative concentrations in central Sichuan, central Shaanxi and Chongqing. Built-up area of agricultural production zones was mainly located in eastern coastal region, including large parts of Hebei, Shandong and Jiangsu, central region including large parts of Henan and Anhui, as well as western parts of the northeastern region. Built-up area of key ecological function zones was relatively dispersed and scattered across the country (Figure 3).

\subsection{Characteristics and regional differences of built-up area from Major Func- tion-oriented Zones}

The national expansion in built-up area in the period 2000-2010 mostly took place in the eastern coastal and central regions, with fast expansion also occurring in southern areas of China's northeast and southern Gansu, eastern Sichuan and Chongqing in the west. Of these, areas with the most obvious increases in built-up area were located in Beijing and Tianjin, the Yangtze River Delta, the Pearl River Delta, Chongqing and Chengdu, with relatively increases in built-up area also occurring around provincial capitals in the central region (Figure 4a). Areas with the most notable increases in built-up area during the period 2010-2013 were mainly located in the Yangtze River Delta, followed by the Bohai Sea region, with insignificant increases in most of the northeastern regions (Figure 4b). 


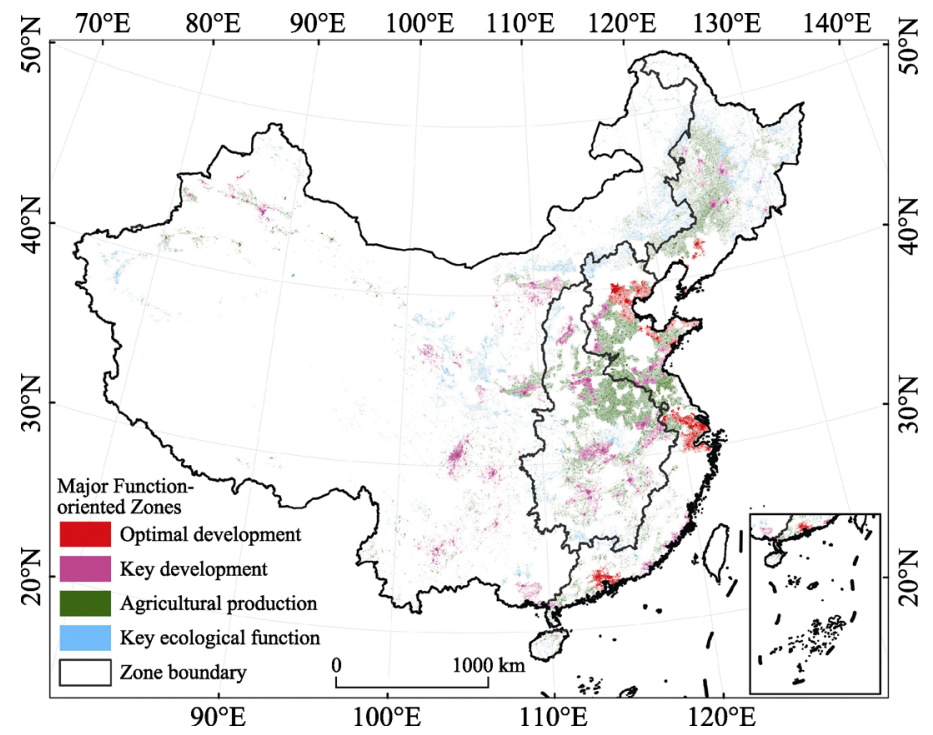

Figure 3 Spatial distribution of built-up area from Major Function-oriented Zones in 2013
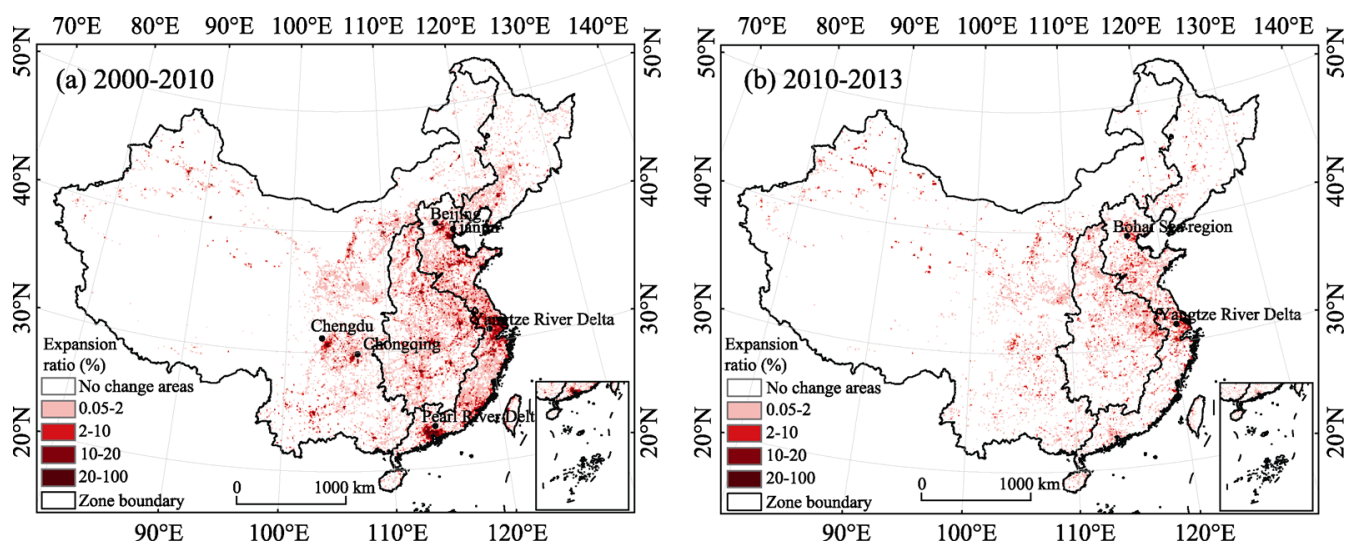

Figure 4 Urban expansion for Major Function-oriented Zones in China in 2000-2010 and 2010-2013

Compared to the period 2000-2010, the area of built-up area in four Major Functionoriented Zones increased to varying degrees (Figure 5b) in the period 2010-2013. The largest increase for 2000-2010, $986.32 \mathrm{~km}^{2} / \mathrm{yr}$, took place in optimal development zones, whereas the same zones registered much slower growth in the period 2010-2013, with key development zones having the largest increase of $1746.27 \mathrm{~km}^{2} / \mathrm{yr}$ (Table 4). Compared to the former 10-year period, the latter three years saw a significant decrease in the growth rate of built-up area in optimal development zones, but a significant increase in the growth rate in other MFOZs (Figure 5c). Key development zones, for example, experienced a rate of change of $4.68 \% / y r$, while the rate of change in key ecological function zones was 2.79 times faster for 2010-2013 compared with 2000-2010, though their average area of expansion remained the lowest (see Table 4). Moreover, during the last three years of the study period, the dynamic degree of each type of major function-oriented zone improved. Optimal development zones had the lowest increase, while key ecological function zones had the highest (Figure 5d). However, during the period 2010-2013, optimal development zones had the most dynamic built-up area, with a value of $0.79 \% / y r$, and although dynamic degree was 
basically the same as the previous 10 years, they were still more dynamic than the three other types of Major Function-oriented Zones (Table 4).
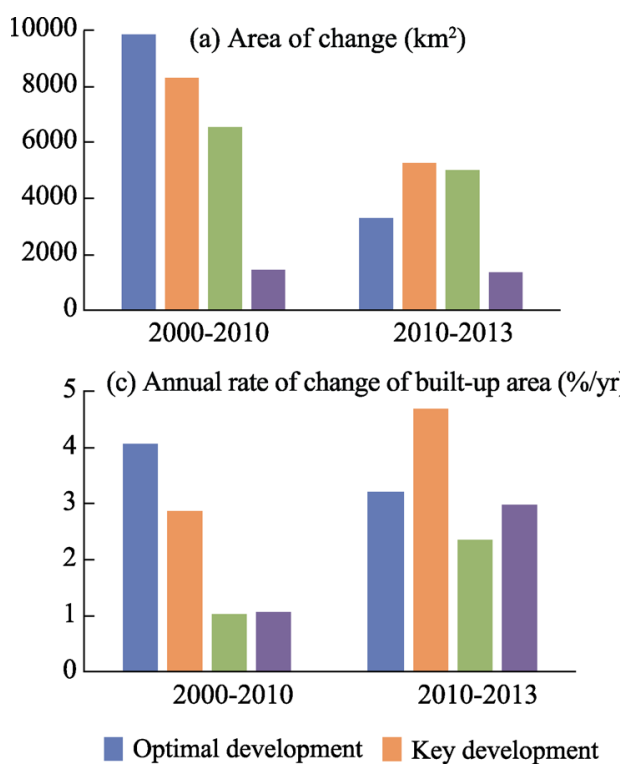
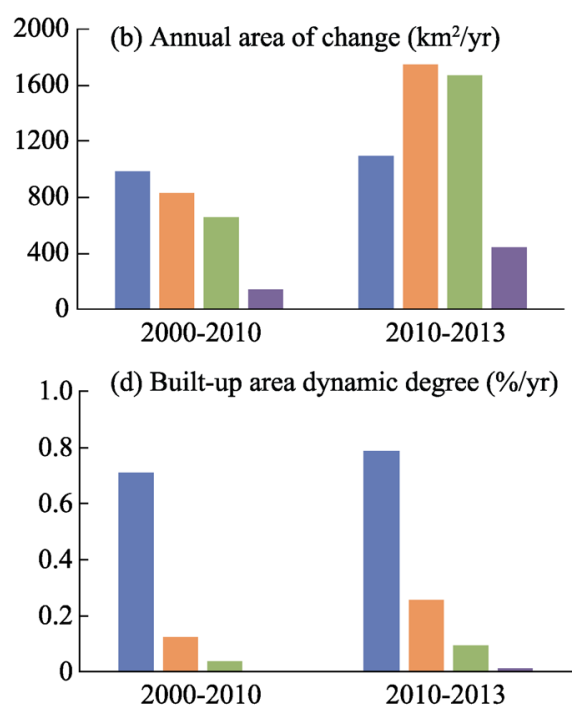

Agricultural production $\square$ Key ecological function

Figure 5 The charts of urban expansion related indexes from Major Function-oriented Zones in 2000-2010 and 2010-2013

During the periods from 2000 to 2010 and from 2010 to 2013, the areas of built-up area in four Major Function-oriented Zones all increased. The increased total area of built-up area from 2000 to 2010 is larger than the total increased area of built-up area from 2010 to 2013. But the annual area and annual rate of increased built-up area are of great difference between the four MFOZs. In the optimal development zones, the annual increased area of built-up area in 2010-2013 is almost the same with the one in 2000-2010, only with a little increase. And the annual increase rate decreased slightly. The expansion of built-up area in optimal development zones is mainly from the expansion of the large and medium scale cities. The increased area of built-up area is mainly from the encroachment of urban built-up area in the farmland around the city and suburbs. In the optimal development zones, which are the eastern coastal and the northeastern regions, the expansion shows a "slow down in the south, keep flat in the north, and speed up in the central part" spatial pattern. Compared to the previous decade, the annual change area and annual change rate of built-up area in the key development zones increased a lot in 2010-2013, almost twice the previous decade. The increase of built-up area is mainly from the sprawling of the rural and urban land. On the national scale, the expansion of built-up area in the key development zones shows a trend of "sharp acceleration in the western and northeastern, keep essentially slowing growth in the central and eastern coastal regions". Compared with the previous decade, the annual change area and rate of built-up area in agricultural production zones increased significantly in 2010-2013. The annual change area has increased by 1.5 times while the annual change rate has increased by 1.3 times. The expansion of built-up area in the agricultural production zones shows a trend of "significant growth in the whole region, abrupt acceleration in the western". In the key ecological function zones, compared to the 2000-2010, the annual 
change area of the built-up area increased by about 2 folds and the annual change rate increased by about 1.8 times during the period 2010-2013. The expansion of built-up area in the key ecological function zones shows a trend of "significant growth in the whole region, abrupt acceleration in the western part, and slowdown in the northeastern part". Both in the agricultural production zones and key ecological function zones, the increase of built-up area include the expansion of both urban land and rural settlements. But because of the high proportion of the rural residential area, the expansion of built-up area is mainly because of the expansion of the rural residential land.

Overall, since the plan for Major Function-oriented Zones was promulgated, the rate of expansion of built-up area in optimal development zones has been effectively controlled and the annual rate of change has decreased significantly. However, because of a smaller total area, with a relatively large scope of built-up area to develop, the optimal development zones would remain most dynamic during the latter three-year study period. This shows that to some extent, since the implementation of the Major Function-oriented Zones plan, the urbanization process in optimal development zones has been transformed from a simple expansion of the urban land to the optimization of urban structure which is an optimum development direction. However, the annual rate of change and dynamic degree of built-up area in key development zones, agricultural production zones and key ecological function zones during the period 2010-2013 increased greatly. The high rate of and intense expansion of built-up area in key development zones shows that the urbanization in key development zones is speeding up. This is the most direct show of the performance of the Major Function-oriented Zones plan in the key development zones. Although the rate of change and dynamic degree of built-up area in agricultural production zones and key ecological function zones was still quite low in the last three years of the study, compared with the first 10 years of the 21 st century, the growth rate was still excessive and not in line with the level required for "restricted development" in the MFOZ plan.

\subsection{Characteristics and regional differences of built-up area from optimal develop- ment zones}

There was fast expansion of built-up area in optimal development zones during the period 2000-2010, particularly in the Yangtze River Delta and Pearl River Delta regions, as well as in Beijing, Tianjin and Shenyang. Built-up area expansion in the $10 \mathrm{~km} \times 10 \mathrm{~km}$ grids exceeded $10 \%$ on average, and in some cities with rapid economic growth, such as Guangzhou, Shenzhen, Beijing, Tianjin, Shanghai, Suzhou and Wuxi, expansion of built-up area in each $10 \mathrm{~km} \times 10 \mathrm{~km}$ grid exceeded 20\% (see Figure 6a). Compared to the previous decade, the speed of expansion of built-up area in many optimal development zones decreased, most noticeably in the Pearl River Delta, while Beijing, Tianjin and their surrounding areas experienced only small increases, and built-up area in the Yangtze River Delta region continued to increase significantly in the three years after the plan for Major Function-oriented Zones was promulgated (Figure 6b).

In terms of the amount, the annual area change of built-up area in the Pearl River Delta decreased from $261.44 \mathrm{~km}^{2} / \mathrm{yr}$ during the first 10 -year study period to $104.28 \mathrm{~km}^{2} / \mathrm{yr}$ in the latter three-year study period, the largest decrease of the five regions under comparison. The annual area change of built-up area in the Yangtze River Delta increased rapidly from 414.34 

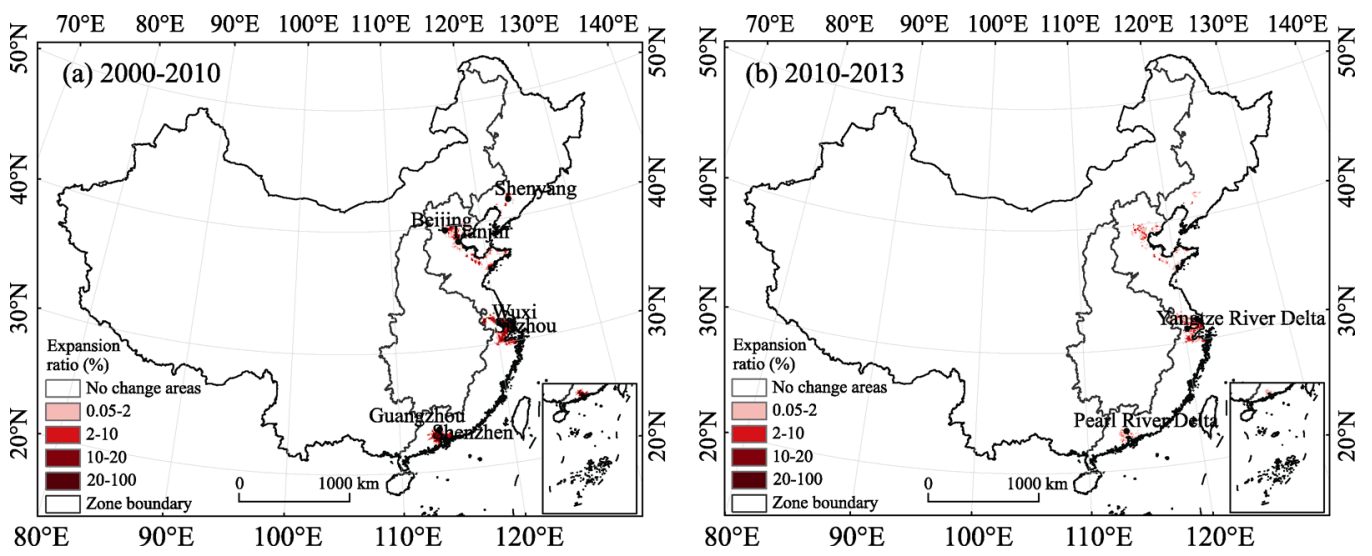

Figure 6 Spatial distribution of urban expansion in optimal development zones in China in 2000-2010 and 2010-2013

$\mathrm{km}^{2} / \mathrm{yr}$ during the first study period to $634.96 \mathrm{~km}^{2} / \mathrm{yr}$ in the second, the biggest increase of the five regions. The other regions did not show significant increases or decreases (Figure 7b). Compared with the period 2000-2010, although there was a small increase in the annual rate of change of built-up area in southern and central Liaoning and the Shandong Peninsula in the period 2010-2013, the annual rate of change in the other three regions fell, with the most significant fall occurring in the Pearl River Delta, where the annual rate of change decreased by $5.1 \% / \mathrm{yr}$ between the two periods. By comparison, the annual rate of change increased by $0.51 \% / y r$ between the two periods in the Shandong Peninsula, the highest increase of all the regions in the study (Figure 7c).

By analyzing dynamic degree of built-up area, the regions with the large changes in built-up area during the two study periods were the Yangtze River Delta and the Pearl River Delta. During the latter study period (2010-2013), the dynamic degree of built-up area in the Yangtze River Delta reached $1.46 \% / \mathrm{yr}$, an increase of $0.51 \% / \mathrm{yr}$, while the dynamic degree of built-up area in the Pearl River Delta decreased by $0.63 \% / y r$, reaching $0.42 \% / y r$. The dynamic degree of other regions showed no significant change (Figure 7d).

Overall, since promulgation of the plan for Major Function-oriented Zones, the speed and intensity of urban expansion in the Pearl River Delta has slowed quite markedly compared to the period before the plan's promulgation, while the spatial layout of development of built-up area was improved significantly. By contrast, the speed and intensity of urban expansion in the Yangtze River Delta and Shandong Peninsula increased rather than decreased, most notably in the Yangtze River Delta, with considerably greater annual increases than the other optimal development zones. The speed and intensity of urban expansion in the Beijing-Tianjin-Hebei region and central and southern Liaoning remained roughly the same before and after the plan's promulgation.

\subsection{Characteristics and regional differences of built-up area from key development zones}

Urban expansion in key development zones in the period 2000-2010 mainly took place in the eastern coastal region, central region and eastern part of the western region. Areas with the most notable urban expansion included the border area between Shandong and Jiangsu in 

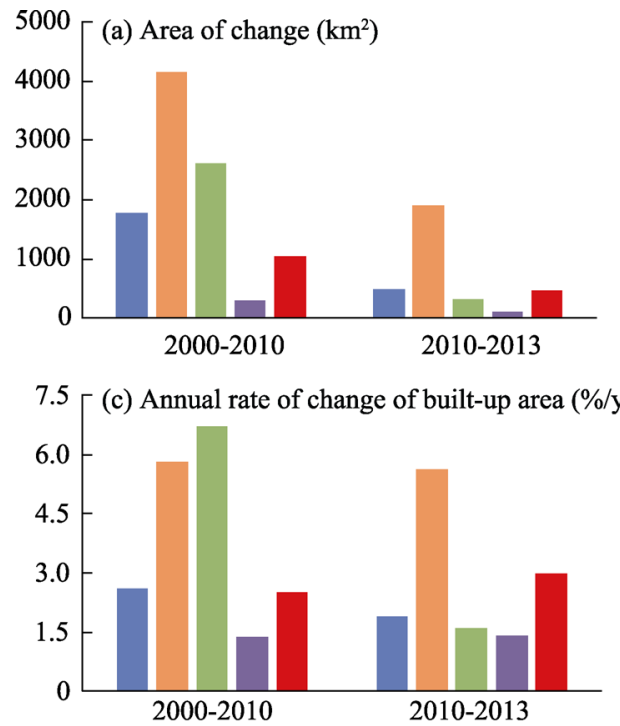
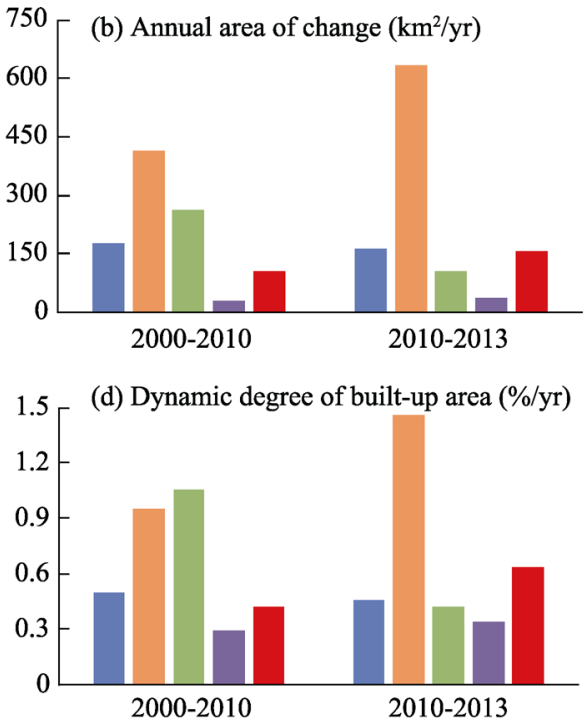

Beijing-Tianjin-Hebei $\square$ Yangtze River Delta $\square$ Pearl River Delta $\square$ Central and southern Liaoning $\square$ Shandong Peninsula

Figure 7 Urban expansion statistics of optimal development zones in China in 2000-2010 and 2010-2013

the eastern coastal region; Changchun in Jilin and Harbin in Heilongjiang in the northeastern region; central Shanxi, northern Henan, eastern Hubei, northeastern Hunan, northern Jiangxi, and central and southern Anhui in the central region; and Erdos in Inner Mongolia, Chengdu in Sichuan, Chongqing, Kunming and Yuxi in Yunnan, and around Urumqi in Xinjiang in the western region (Figure 8a). The distribution of urban expansion in key development zones during the period 2010-2013 was similar to the decade before, with the most significant growth occurring in the eastern, central and southern parts of Anhui Province, Erdos in Inner Mongolia, Chengdu in Sichuan and Urumqi in Xinjiang (Figure 8b).

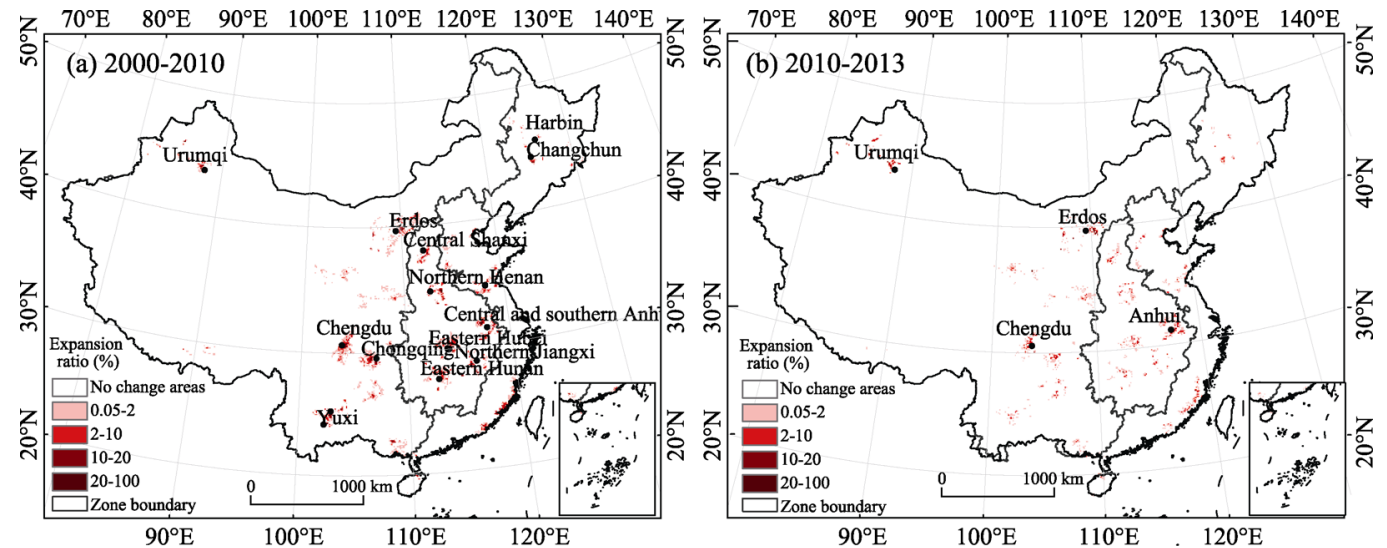

Figure 8 Spatial distribution of urban expansion in key development zones in China in 2000-2010 and 2010-2013

The annual area change of built-up area in the four main regions increased to varying degrees. The western region had the greatest increase in the last three years of the study period compared to the previous ten years, increasing from $326.17 \mathrm{~km}^{2} / \mathrm{yr}$ to $832.77 \mathrm{~km}^{2} / \mathrm{yr}$. Moreover, although the overall amount of annual area change in the northeast was relatively small, 
it showed the greatest increase, of 2.85 times, compared to the previous decade. The eastern coastal region and northeast had the smallest increases (Figure 9b).

In the period 2010-2013, the western region had the highest annual rate of change of built-up area, reaching $6.65 \% / y r$, and the northeastern region had the highest increase over the previous decade, from $1.10 \% / \mathrm{yr}$ to $2.82 \% / \mathrm{yr}$ (Figure $9 \mathrm{c}$ ).
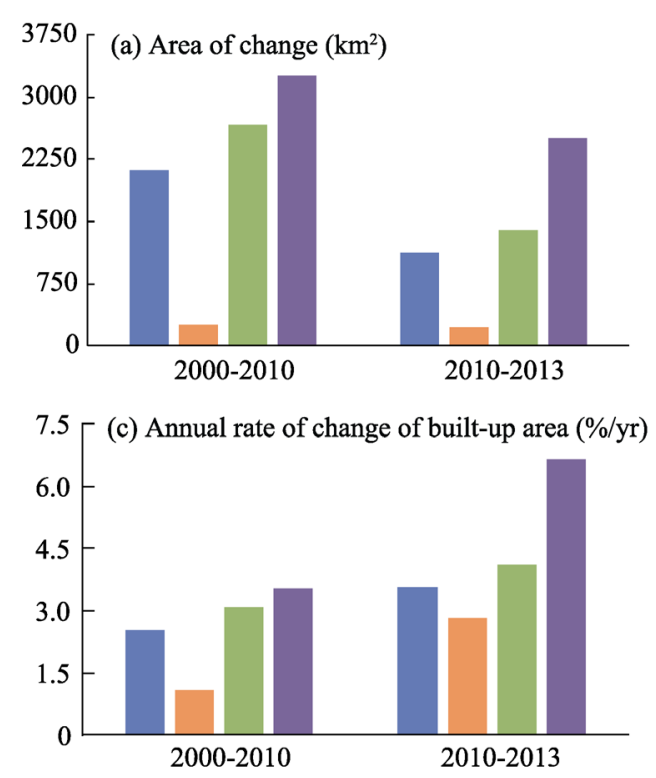
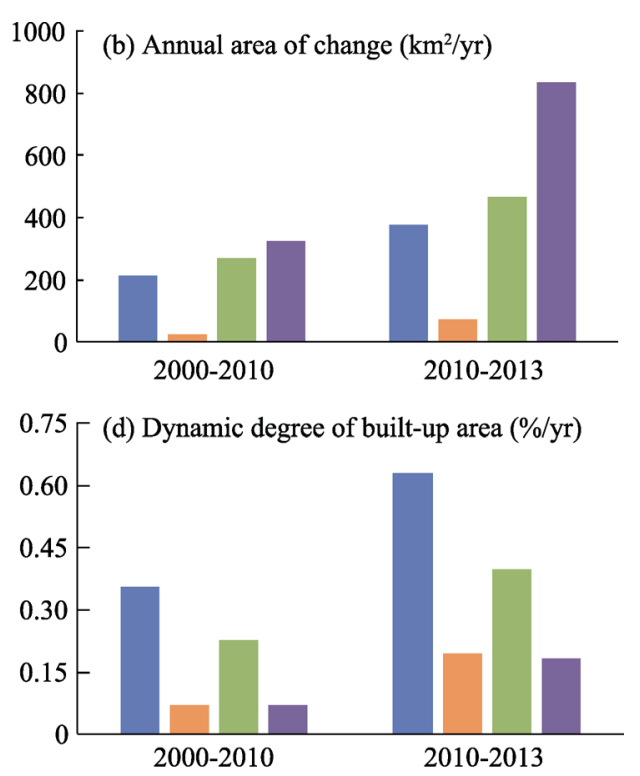

Eastern coastal region Northeastern region Central region $\square$ Western region

Figure 9 Urban expansion statistics of key development zones in China in 2000-2010 and 2010-2013

In terms of the dynamic degree of built-up area, the eastern coastal region continued to have the highest rate in the period 2010-2013, with $0.63 \% / y r$, while the northeastern and western regions had the largest increases of 2.86 and 2.57 times, respectively, between the two periods (Figure 9d).

Overall, following promulgation of the plan for Major Function-oriented Zones, the average annual area of expansion of built-up area in key development zones exceeded that of optimal development zones, and all four major regions showed increases in the speed and intensity of expansion, most notably the northeastern and western regions. The western region also experienced the highest growth of all regions in terms of annual area increases and speed of growth. The eastern coastal and central regions increased at a slower rate, but urban expansion in each region was basically in line with the requirements set out in the plan for Major Function-oriented Zones.

\subsection{Characteristics and regional differences of built-up area from agricultural pro- duction zones}

Expansion of built-up area in agricultural production zones was relatively dispersed during the period 2000-2010, being scattered around the eastern coastal, central and southern part of northeastern regions, as well as the southeast corner of the western region. Although expansion of built-up area in agricultural production zones occurred throughout the country, overall levels were relatively low. Areas with agricultural production zones that experienced 
relatively high levels of expansion included the border area between Hebei and Shandong and the majority of Jiangsu and Fujian provinces in the eastern coastal region, Liaoning Province and western Jilin in the northeastern region, Henan, Anhui, Hunan and Hubei provinces in the central region, and Sichuan, Yunnan and Guizhou provinces and northern Xinjiang in the western region (Figure 10a). Compared to the previous decade, there was relatively little urban expansion in agricultural production zones during the period 2010-2013, and it was mainly concentrated in Henan, Shandong and Anhui provinces (Figure 10b).
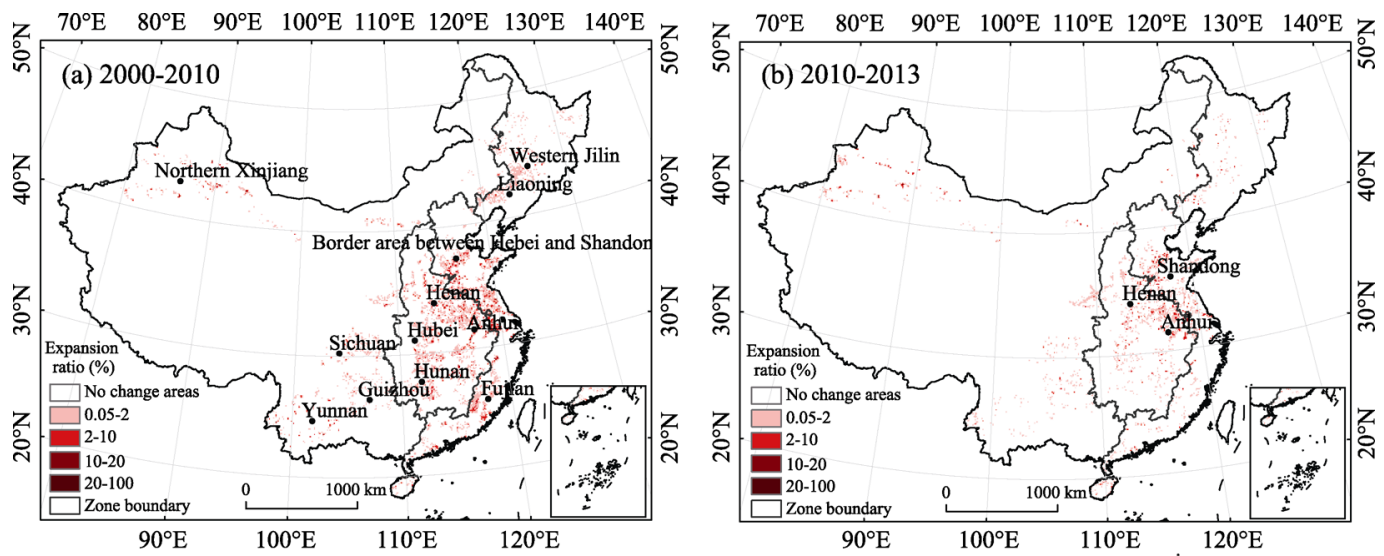

Figure 10 Spatial distribution of urban expansion in agricultural production zones in China in 2000-2010 and 2010-2013

Agricultural production zones in the eastern coastal region had the largest annual area of change in built-up area in the period 2010-2013 (590.47 km $/ 2 \mathrm{yr})$, while the western region experienced the fastest growth $\left(442.36 \mathrm{~km}^{2} / \mathrm{yr}\right)$, which was 3.77 times more than the previous decade. Meanwhile, the northeastern and central regions also experienced significant increases (Figure 11b). The annual rate of change of built-up area in the period 2010-2013 was the fastest compared to the previous decade in the western region, which also had the highest overall amount, with $5.79 \% / y r$. The rate of change of built-up area in agricultural production zones in the other three regions all showed varying degrees of growth (Figure 11c).

Agricultural production zones in the eastern coastal region also had the most dynamic built-up area, with values of $0.11 \% / \mathrm{yr}$ in the period $2000-2010$ and $0.22 \% / \mathrm{yr}$ in the period 2010-2013, while the western region had the largest increase in dynamic condition, from $0.01 \% / \mathrm{yr}$ in the period $2000-2010$ to $0.05 \% / \mathrm{yr}$ in the following three-year period, a five-fold increase. In addition, agricultural production zones in the central region experienced a significant increase in dynamic degree from $0.05 \% / \mathrm{yr}$ in the period $2000-2010$ to $0.14 \% / \mathrm{yr}$ in the period 2010-2013 (Figure 11d).

Overall, since the plan for Major Function-oriented Zones was promulgated, the average annual area expansion of built-up area in agricultural production zones has exceeded that of optimal development zones. The annual rate of increase in area of built-up area in agricultural production zones in the eastern coastal, central and western regions in the 2010-2013 period was more than double that of the previous 10-year period, while the annual rate of 
increase in the western region was more than three times that of the previous period. Moreover, the speed and intensity of urban expansion in the four major regions also increased significantly, with the most notable increases occurring in the western region. With the exception of a few localities, the annual rate of change and dynamic degree of urban expansion in agricultural production zones in each of the main regions were below those in key development zones, which largely conformed to the requirements set out in the plan for Major Function-oriented Zones.
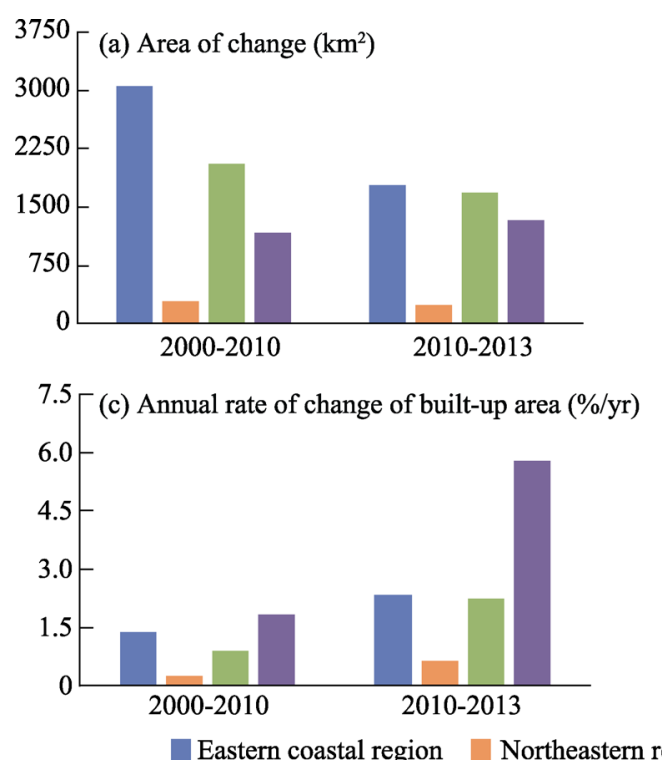
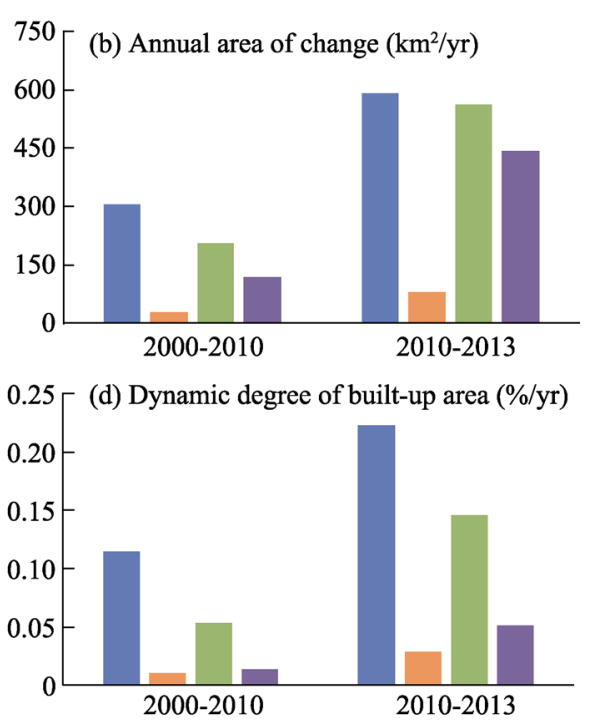

Central region Western region

Figure 11 Urban expansion statistics of agricultural production zones in China in 2000-2010 and 2010-2013

\subsection{Characteristics and regional differences of built-up area from key ecological function zones}

There was relatively little and scattered expansion of built-up area in national key ecological function zones, with less than $2 \%$ of $10 \mathrm{~km} \times 10 \mathrm{~km}$ grids registering expansion. The little expansion that took place in the period 2000-2010 was mainly focused in eastern Hubei and the border areas of Hubei, Hunan and Chongqing in the central region, as well as eastern Inner Mongolia, southern Gansu and large parts of Shaanxi in the western region (Figure 12a). During the period 2010-2013, very little expansion of built-up area took place in key ecological function zones (Figure 12b).

Built-up area in key ecological function zones within each of the major regions expanded by a relatively small amount, with the western region showing the largest annual area of change, from $82.58 \mathrm{~km}^{2} / \mathrm{yr}$ in the period $2000-2010$ to $294.69 \mathrm{~km}^{2} / \mathrm{yr}$ in the period 2010-2013, which was also the fastest rate of growth, followed by the central region, with an annual area of change 3.01 times higher in the latter period than the former (Figure 13b).

The rate of change of built-up area in key ecological function zones in the central region reached 6.66\%/yr in the period 2010-2013, the highest of the four major regions. During the same period, the rate of change of built-up area in key ecological function zones greatly exceeded that of built-up area in agricultural production zones and key development zones 


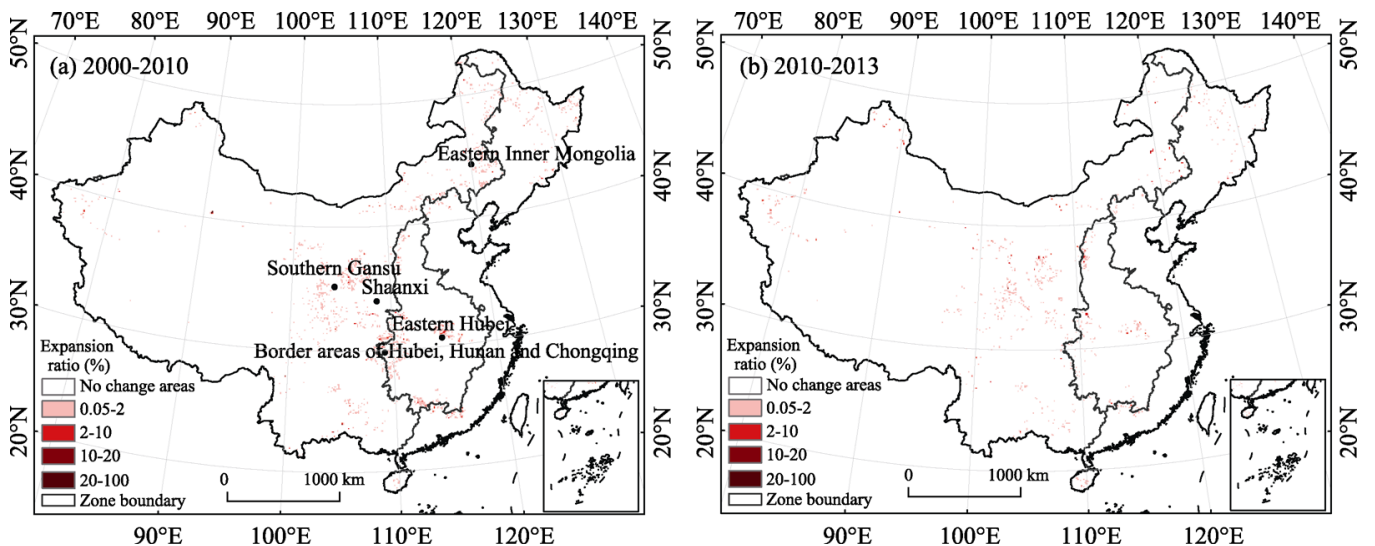

Figure 12 Spatial distribution of urban expansion in key ecological function zones in China in 2000-2010 and 2010-2013

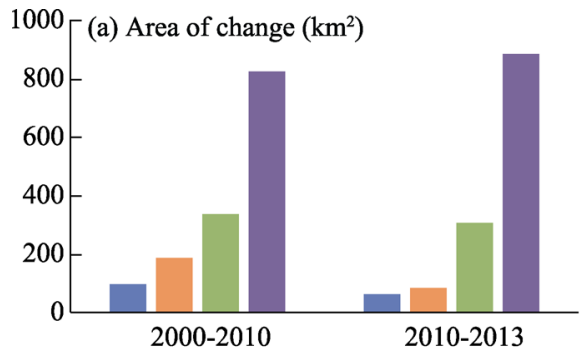

(c) Annual rate of change of built-up area (\%/yr)

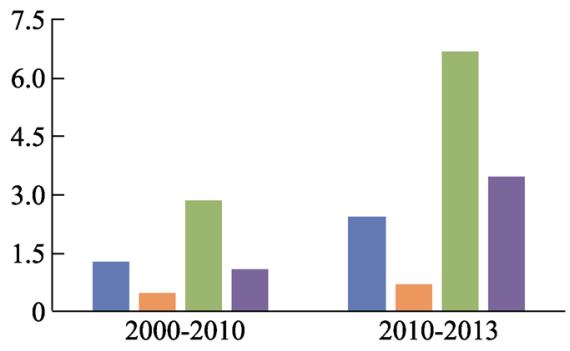

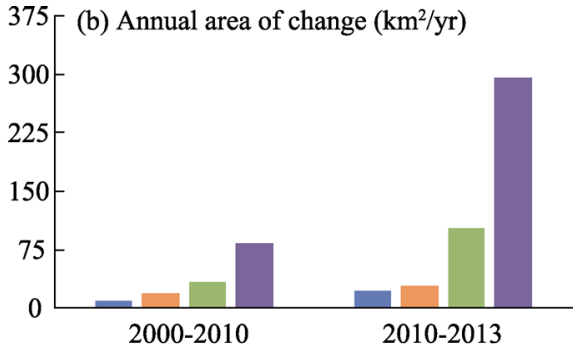

(d) Dynamic degree of built-up area (\%/yr)

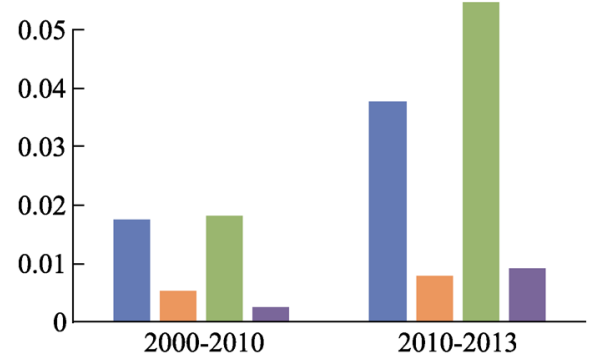

Central region Western region

Figure 13 Urban expansion statistics of key ecological function zones in China in 2000-2010 and 2010-2013

(Figure 13c). Meanwhile, the western region experienced the largest increase in the rate of built-up area change, 3.23 times higher in the period 2010-2013 than in the period 2000-2010. The eastern coastal region had the most dynamic built-up area in key ecological function zones in both periods, being $0.02 \% / \mathrm{yr}$ and $0.04 \% / \mathrm{yr}$, respectively, while the western region had the fastest growth rate in terms of dynamic condition, with the latter period 3 times higher than the former period, though the total value was quite low, only $0.009 \% / y r$ for 2010-2013 (Figure 13d).

Overall, then, following promulgation of the plan for Major Function-oriented Zones, the speed and intensity of urban expansion in key ecological function zones increased to varying degrees in each of the four major regions, with the most notable increase in the western region and the weakest growth rate in the northeastern. It is worth noting that there was a significant increase in the annual rate of change and dynamic degree of urban and rural con- 
struction in the central region, with the annual rate of change considerably higher than agricultural production zones, and even higher than key development zones. It is therefore necessary to further strengthen management and control over this.

\section{Conclusions}

By interpreting built-up area expansion data from multiple periods from CLUD Major Function-oriented Zoning in China, the spatiotemporal characteristics of the expansion of built-up area were analyzed in the first decade of the 21 st century and during the following three years. Using the indexes including the annual rate of change and dynamic degree of built-up area, this paper has revealed the characteristics and causes of changes in built-up area across the country and in the MFOZs located in the four major regions (eastern, central, western and northwestern) before and since promulgation of the plan for Major Function-oriented Zones.

(1) In 2013, built-up area in optimal development zones, key development zones, agricultural production zones and key ecological function zones as a proportion of the total land area in each of the zones was $27.02 \%, 6.27 \%, 4.18 \%$ and $0.43 \%$, respectively. Urban built-up area accounted for $50.82 \%, 36.4 \%, 18.33 \%$ and $16.85 \%$ of the total built-up area in each type of zones, respectively, while rural built-up area was the opposite, which reflects the cascading nature of national land use in accordance with the layout of major functions.

(2) Compared with the period 2000-2010, annual growth in built-up area in optimal development zones decreased during 2010-2013, while it increased significantly in key development zones, agricultural production zones and key ecological function zones, with the average area expansion of urban and rural construction in key development zones and agricultural production zones exceeding that of optimal development zones, and the annual average area expansion of built-up area in key ecological function zones and the dynamic degree of urban and rural land remaining the lowest levels.

(3) At the regional scale, the average annual increase in built-up area in optimal development zones in the Yangtze River Delta region was significantly higher than that in optimal development zones in other regions; the average area increase and rate of increase of builtup area in key development zones was faster in the western region than in other regions; average annual area growth of built-up area in agricultural production zones in the northeastern, central and western regions was twice as high as the previous decade on average, while the annual rate of increase in the western region was three times as high as in the previous decade; the annual rate of change and increase in the dynamic degree of built-up area were most notable in key ecological function zones in the central region.

(4) The spatial pattern and characteristics of built-up area from 2010 to 2013 reflected the gradient feature development requirements of the plan for Major Function-oriented Zones. But the rate of increase locally in built-up area in optimal development zones, agricultural production zones and key ecological function zones is excessive, so management and regulation must be strengthened.

(5) This study indicated that by adopting a spatial-pattern change analytical method to carry out an analysis of the characteristics and the regional differences of built-up area in the periods before and after the promulgation of the plan for Major Function-oriented Zones, the variation in built-up area in different functional zones and different regions and the degree 
that such variation corresponds to the plan for Major Function-oriented Zones is made clear. The study indicated these methods and results were meaningful for future regulation strategies in optimizing national land development in China.

\section{References}

Chen Y Y, 2004. Some views on regional adaptation to global change research. Advances in Earth Science, 19(4): 495-499. (in Chinese)

Fan J, 2015. Draft of Major Function Oriented Zoning of China. Acta Geographica Sinica, 70(2): 186-201. (in Chinese)

Fan J, Sun W, Yang Z S et al., 2012. Focusing on the Major Function-oriented Zone: A new spatial planning approach and practice in China and its 12th Five-Year Plan. Asia Pacific Viewpoint, 53(1): 85-95.

Fan J, Sun W, Zhou K et al., 2012. Major Function Oriented Zone: New method of spatial regulation for reshaping regional development pattern in China. Chinese Geographical Science, 22(2): 1-14.

Foley J A, DeFries R, Asner G P et al., 2005. Global consequences of land use. Science, 309(5734): 570-574.

GLP Science Plan and Implementation Strategy (GLP), 2005. IGBP Report No.53/IHDP Report No.19, Stockholm, 64.

Kuang W H, Liu J Y, Zhang Z X et al., 2013. Spatiotemporal dynamics of impervious surface areas across China during the early 21 st century. Chinese Science Bulletin, 14: 1-11.

Lambin E F, Baulies X, Bockstael N et al., 1995. Land-use and land-cover change (LUCC): Implementation strategy. A Core Project of the International Geosphere-Biosphere Programme and the International Human Dimensions Programme on Global Environmental Change. IGBP Report 48. IHDP Report 10. IGBP, Stockholm, 125.

Liu J Y, 1996. Macro-scale Survey and Dynamic Study of Natural Resources and Environment of China by Remote Sensing. Beijing: China Science and Technology Press. (in Chinese)

Liu J Y, Kuang W H, Zhang Z X et al., 2014. Spatiotemporal characteristics, patterns and causes of land use changes in China since the late 1980s. Acta Geographica Sinica, 69(1): 3-14. (in Chinese)

Liu J Y, Zhang Z X, Xu X L et al., 2010. Spatial patterns and driving forces of land use change in China during the early 21 st century. Journal of Geographical Sciences, 20(4): 483-494.

Liu J Y, Zhang Z X, Zhuang D F et al., 2003. A study on the spatial-temporal dynamic changes of land-use and driving forces analyses of China in the 1990s. Geographical Research, 22(1): 1-12. (in Chinese)

Liu Y B, Li R D, Song X F, 2005. Grey associative analysis of regional urbanization and eco-environment coupling in China. Acta Geographica Sinica, 60(2): 237-247. (in Chinese)

Lu D D, Fan J, 2009. 2050: The Regional Development of China. Beijing: Science Press. (in Chinese)

McMahon G, Benjamin S P, Clarke K et al., 2005. Geography for a Changing World: A Science Strategy for the Geographic Research of the U.S. Geological Survey, 2005-2015, Sioux Falls. SD: U.S. Geological Survey Circular, 1281: 1-76.

Salazar A, Baldi G, Hirota M et al., 2015. Land use and land cover change impacts on the regional climate of non-Amazonian South America: A review. Global \& Planetary Change, 128: 103-119.

Shi P J, Gong P, Li X B et al., 2000. Methods and Practice of Land Use/Cover Change. Beijing: Science Press. (in Chinese)

Turner B L, Skole D, Sanderson S et al., 1995. Land-use and land-cover change: Science/research plan. Joint Publication of the International Geosphere-Biosphere Programme (Report No.35) and the Human Dimensions of Global Environmental Change Programme (Report No.7). Stockholm: Royal Swedish Academy of Sciences.

Turner B L, Skole D, Sanderson S et al., 1995. Land Cover Change Science/Research Plan, IGBP Report No. 35, HDP Report 7. IGBP of the ICSU and HDP of the ISSC, Stockholm and Geneva.

Zhang Z X, Zhao X L, Wang X et al., 2012. Remote Sensing Monitoring of Land Use in China. Beijing: Star Maps Publishing House. (in Chinese) 